\title{
UMA HISTÓRIA AMBIENTAL RIO-GRANDINA: O PROJETO “ADEUS AOS LIXÕES” E SEUS RESULTADOS
}

\author{
Hardalla Santos do Valle ${ }^{1}$ \\ Daniel Porciuncula Prado ${ }^{2}$ \\ Mário Fernando Carvalho Ribeiro ${ }^{3}$
}

Resumo: Muito se discute sobre o que realmente deve ser feito para gerar um amanhã mais digno e igualitário, principalmente, dentro das universidades. Com efeito, o que estamos propondo neste trabalho é a análise sobre o projeto "Adeus aos lixões", que colocou em prática a teoria adquirida na academia, construindo dessa forma uma intervenção socioambiental na comunidade riograndina. São questões de pesquisa deste artigo: Quais os resultados do projeto "Adeus aos lixões"? Essa intervenção teve resultados permanentes? $\mathrm{Na}$ busca pela aproximação desse cenário, foram escolhidas as metodologias da pesquisa bibliográfica e análise documental. Assim sendo o objetivo disseminar e fomentar novos conhecimentos acerca da História Ambiental da cidade do Rio Grande.

Palavras-Chave: História Ambiental; Resíduos Sólidos; Meio Ambiente.

\footnotetext{
1 Doutoranda do Programa de Pós-Graduação em Educação da Universidade Federal de Pelotas. E-mail: hardalladovalle@gmail.com.

2 Professor Adjunto da Universidade Federal do Rio Grande (FURG). Doutor em Educação Ambiental pelo Programa de Pós-Graduação em Educação Ambiental da FURG. E-mail: danielhistprado@yahoo.com.br.

3 Professor da Universidade Federal do Rio Grande (FURG). Mestrando em Educação Ambiental pela Universidade Federal do Rio Grande. E-mail: mozzo@vetorial.net.
}

Revbea, São Paulo, V. 9, Nº 1: 157-168, 2014. 


\section{INTRODUÇÃO}

"Podemos falar sobre o futuro, visualizar o futuro, mas se queremos este futuro teremos que agir".

Daryl Kollman

Como afirma Daryl Kollman, ainda se discute dentro das academias sobre teorias e hipóteses para a conquista de um mundo sustentável No entanto as ações em prol desse ideal permanecem restritas. Assim sendo, este trabalho propõe a análise sobre o projeto "Adeus aos lixões" que colocou em prática a teoria adquirida na academia, construindo dessa forma, uma intervenção socioambiental que estimulou e ocasionou uma mudança comportamental na comunidade local da época.

Implantado em 1990, o projeto "Adeus aos lixões" atuou na iniciativa da coleta seletiva de lixo na cidade do Rio Grande/RS, prática da educação ambiental em escolas e universidade, e no incentivo à cooperativa de catadores de lixo para realização da necessária separação de resíduos e posterior geração de trabalho e renda.

Contudo, mesmo com sua forte atuação, o projeto, ao longo dos anos, foi sendo esquecido e os hábitos outrora cultivados enfraquecidos, restando somente a todos aqueles que vivenciaram o seu auge questionar: Quais os resultados do projeto "Adeus aos Lixões"? Essa intervenção teve resultados permanentes? Quais os vestígios que se pode observar dessa história?

$\mathrm{Na}$ busca por respostas, foi aqui utilizada a análise documental, que parte da mensagem, mas considera as condições contextuais de seus produtores e assenta-se na concepção crítica e dinâmica da linguagem, objetivando interpretar o sentido que um indivíduo atribui às mensagens (CELLARD, 2008).

Discorrendo ainda sobre a metodologia, não podemos esquecer a história oral que possibilita compreender, construir e reconstruir a história a partir de relatos individuais e coletivos (MENEGOLO, 2006).

Entre as bases teóricas, deve-se destacar a História Ambiental, que traz a importância da relação homem-natureza na elaboração do conhecimento histórico.

Assim sendo, é importante salientar que o objetivo deste artigo é provocar a devida reflexão a uma preciosa luta, pela consciência socioambiental, que faz parte da história da cidade do Rio Grande. Além disso, é pretendido instigar a analise e consciência de quem lê acerca da questão dos resíduos sólidos, da necessidade de uma coleta seletiva diferenciada e da urgência por mudanças. 


\title{
O PROJETO
}

Essa parte do trabalho versa sobre as informações e especificidades contidas no projeto original de "Adeus aos Lixões", para a compreensão das intenções e abrangências contidas nesses escritos.

\begin{abstract}
Pois bem, a estória que vão poder contar, daqui a algum tempo, é que, aqui em nossa cidade, começou-se a mudar a cabeça das pessoas, através de um processo de conscientização, exatamente no dia mundial do meio ambiente, no ano de 1989 (OLIVEIRA, 1996, p.57).
\end{abstract}

Como foi exposto na citação de Artur Oliveira, autor do projeto, "Adeus aos Lixões" foi criado em maio de 1989. A iniciativa desse projeto foi oriunda da análise de docentes da Universidade Federal do Rio Grande (FURG) sobre a realidade de desleixo com o meio, falta de consciência socioambiental da população e necessidade de uma coleta seletiva na cidade do Rio Grande.

Primeiramente, é importante salientar que na época da elaboração de "Adeus aos Lixões" o serviço de limpeza pública da cidade, órgão da Secretaria Municipal dos Serviços Urbanos, utilizava um lixão situado no Bolaxa (próximo à praia do Cassino) para o destino final do lixo urbano. Esse, por ser construído em área privada, possuía um tempo incerto para sua utilização. Além disso, a questão ambiental não era uma preocupação para os órgãos públicos dirigentes e nem para os habitantes da cidade que pouco, ou nada, faziam sobre a precariedade do local e dos serviços.

E nesse panorama é que "Adeus aos lixões" demonstra toda sua importância, visto que, estabeleceu uma luta pela evolução da consciência ambiental e adesão a coleta seletiva em Rio Grande.

Assim, inicialmente, pensou-se em uma forma de atuação especifica com a finalidade de levar a população uma maneira de se integrar no processo de mudança, na concepção de uma relação mais próxima entre a limpeza pública, o meio Ambiente e a sociedade.

Segundo a documentação analisada, a primeira etapa cogitada foi atingir as escolas municipais. Dessa forma, foram mapeados os estabelecimentos de ensino, para posteriormente visitá-los em sua totalidade, integrando-os no processo educativo.

O projeto previa que em dez semanas, seriam atendidas dez escolas, sendo que, a cada semana deveriam ser oferecidas a essas instituições de ensino oportunidades de participarem de forma ativa nos processos de aprendizagem e avaliação.

Na primeira semana, seria visitada uma escola, onde seriam proferidas palestras nos turnos que os professores pudessem participar. Essas palestras versariam sobre a problemática dos resíduos em Rio Grande e a viabilidade econômica do reaproveitamento e da reciclagem, através da separação do 
material reciclável na origem. Nessa oportunidade seriam traçadas as relações entre os resíduos e o meio ambiente.

Planejado também, estava instituir o "Dia do Lixo". Esse seria um determinado dia da semana que deveria ficar consagrado por marcar a realização, em uma determinada escola, de palestras dirigidas por educadores. Além disso, seria realizada uma coleta seletiva, pela Secretaria Municipal dos Serviços Urbanos, dos resíduos previamente separados e encaminhados para o estabelecimento de ensino.

O material seria recolhido pela Secretaria Municipal dos serviços Urbanos seria conduzido para o espaço destinado a separação por tipo de material, onde também seria feita a avaliação do que foi arrecadado.

\begin{abstract}
Entre as finalidades do projeto podemos salientar a caracterização dos hábitos de populações com atividades semelhantes, a observação dos diferentes comportamentos e resposta no processo de conscientização, a caracterização do lixo em diferentes camadas sociais, a facilitação do processo de realimentação de informações e metodologia adequada para as diversas comunidades, a identificação de interesses particulares setoriados, com zoneamento sanitário e a homogeneidade de comunicação. (Parágrafo retirado do projeto original de "Adeus aos Lixões").
\end{abstract}

Como comentado na citação acima, o procedimento a ser adotado nessa campanha de educação, teria como importância fundamental a definição e avaliação de um universo homogêneo de caráter socioeconômico.

É interessante lembrar ainda, que os objetivos do projeto se dividiam em cinco setores, sendo eles: Educativos, ecológicos, sanitários, sociais, econômicos e legais.

O projeto encerra com uma avaliação, que seria feita com base nos resultados obtidos. Assim, seria considerada a receptividade das escolas, o nível de entendimento dos alunos, a relação do lixo coletado e do número de alunos que foram abordados os recursos obtidos com a comercialização, a relação dos resíduos com a situação socioeconômica da comunidade, a possibilidade de extrapolação para a comunidade envolvida e os métodos aplicados.

Dado o exposto, o projeto aqui apresentado pretendia começar um processo de conscientização socioambiental, enfatizando sua ação na proposta de uma efetiva coleta seletiva com inclusão social.

Sua importância e destaque pautam-se não tão somente pela inclusão no pioneirismo da discussão e trabalho com a temática, como também pela transformação socioambiental acarretada em seu processo. Os resultados que elucidam esse panorama serão expostos a seguir. 


\section{Impactos}

No que tange a prática efetivada do projeto, apresenta-se aqui, por meio da análise documental de atas, ofícios, documentos diversos e também pela História oral um aparato de alguns destaques dentro do que foi realizado.

(...) e aí.. ganhou! O Vidal, né? E o Dirceu ficou como secretário dos serviços urbanos. Assim, em 5 de julho do ano seguinte começou o projeto. ${ }^{4}$ (DUARTE, Eliane. Entrevista realizada em 2010)

Como foi exposto na entrevista, somente a partir da vitória do prefeito Vidal e da posse, enquanto secretário dos serviços urbanos, de Dirceu Lopes, que o projeto "Adeus aos Lixões" pode ser iniciado.

As primeiras ações da equipe do projeto se centraram na divulgação de "Adeus aos Lixões", através de escolas, por meio do "dia do lixo". Assim, esse foi realizado em diversas escolas ${ }^{5}$, abrangendo, segundo Eliane Duarte, todas as escolas da cidade.

No que tange a resposta obtida com esse trabalho, pode-se enfatizar que pela história oral e análise documental de ofícios da Comissão Executiva do Serviço de Destinação de Resíduos, foi possível perceber uma imediata adesão da ideia pelos alunos das escolas da cidade do Rio Grande. Isso porque, houve um aumento considerável no número de resíduos sólidos recolhidos.

Vale salientar um importante fruto do "Dia do Lixo" que foi a criação da primeira associação de catadores da cidade em 1991, a Associação dos Catadores e Separadores de Lixo de Rio Grande (ASCALIXO) ${ }^{6}$.

Ao mesmo tempo em que esse cenário era construído nas escolas e redondezas, dentro da Universidade Federal do Rio Grande, novas conquistas também aconteciam.

Assim sendo, foi criada a Comissão Executiva do Serviço de Destinação de Resíduos que tinha sido idealizada desde o ano de 1989. Essa comissão tinha a função de pesquisar, de forma quantitativa, as especificidades dos resíduos sólidos da universidade e orientar o recolhimento diferenciado no âmbito da FURG? .

\footnotetext{
${ }^{4}$ Entrevista concedida no dia 18 de Novembro de 2010.

${ }^{5}$ Informação comprovada através de documentos de controle da equipe.

${ }^{6}$ Informação extraída a partir da história oral.

7 Informação retirada do Ofício no 791 do ano de 89 da Fundação Universidade Federal do Rio GrandeFURG, assinada pelo reitor do período, Orlando Macedo Fernandes.
} 
É, não! Tipo assim.. a universidade naquela época não queria envolver seu nome com uma loucura! (risadas) Mas aí a coisa começou e não deixou nunca de ser da universidade.. Por quê? Por que eu e o Artur éramos da universidade.. Não tinha o apoio institucional, mas tinha nossa presença, que era a representação da FURG! Mas mesmo assim, depois do movimento a gente fez um projeto.. não era o "Adeus aos lixões" por que esse já tinha começado, era.. Educação ambiental para coleta seletiva, uma coisa assim.. Aí que a gente começou a conseguir coisas da FURG! (DUARTE, Eliane. Entrevista realizada em 2010)

Nesse ponto, é possível perceber, através do trecho acima, que a identidade de "Adeus aos Lixões" pode, e deve, ser vinculada a FURG pelas ações que os atores sociais ${ }^{8}$, que estavam vinculados a universidade, promoveram. No entanto, é preciso que se tenha claro que a prática inicial do projeto deu-se por apoio do órgão municipal. Somente, quando alguns frutos desse trabalho já eram perceptíveis foi que a instituição passou a apoiar a ideia da coleta seletiva e reciclagem.

Assim, os integrantes da equipe, aproveitaram essa oportunidade e escreveram um novo projeto com as mesmas ideias do "Adeus aos Lixões" para obter apoio financeiro e ideológico da FURG, que se chamava "Lixo: Educação comunitária para a coleta diferenciada."

Dessa forma, com uma abertura maior dentro da universidade, destaca-se "aproveitamento do espaço" mais uma vez, a iniciativa de Artur de Oliveira e Eliane Bacchiere Duarte. Esses, levavam constantemente para a sala de aula questões importantes sobre os resíduos sólidos, propondo paralelamente, pequenas atividades conjuntas que acabavam divulgando a problemática.

Para nós a palavra prova tinha dois sentidos: Primeiro, saber se os alunos tinham tomado consciência dos problemas levantados e, em segundo lugar, a pontuação dos alunos pela satisfação de uma tarefa escolar. A professora Eliane Duarte, responsável pelo projeto de extensão "Lixo: Educação comunitária para coleta diferenciada" teve uma daquelas ideias que conseguem adequar a proposta ao objetivo. A questão formulada pela professora seria avaliada através da verificação, no dia da prova, se os alunos tinham ou não lixo separado, por um critério bem simples: Eles trarão o lixo limpo que separarem. Você sabe o que aconteceu? Uma verdadeira procissão de alunos transportando sacolas com lixo limpo, em direção a Universidade (OLIVEIRA, 1993, p.14).

8 Julgo importante aqui destacar, que quando me refiro aos atores sociais do projeto nesse trecho, associo essa "denominação" também a Comissão Executiva do serviço de destinação de resíduos sólidos e todos os discentes e docentes que participaram ministrando as aulas no "Dia do Lixo" ou, simplesmente levando seus resíduos sólidos recicláveis até o galpão multiuso.

Revbea, São Paulo, V. 9, N 1:157-168, 2014. 
Conforme a citação, uma atitude diferenciada na prática docente pode através de uma ação, provocar uma reflexão extremamente importante. Isso porque a partir do momento que os alunos conseguem perceber próximo o problema, podem passar a pensar sobre a necessidade de uma solução e se sentirem estimulados a mudança comportamental.

Outro grande destaque no estímulo a conscientização ambiental foi o projeto "Florestar" que nasceu em 1990, durante as discussões da equipe e dos envolvidos no projeto "Adeus aos Lixões".

Todavia, em meio a tantos acontecimentos que anteriormente foram citados, novamente muda o cenário político local, fato que prejudica 0 andamento do projeto.

Dessa maneira, devido a conflitos políticos e mudanças no quadro administrativo municipal, o apoio passou a ser cada vez menor ao ideário do projeto. Todavia, mesmo sentindo as consequências dessas mudanças os atores sociais de "Adeus aos Lixões" continuaram a ministrar as palestras em escolas e passaram a divulgar a coleta seletiva da cidade, que foi algo conseguido nesse período de transição política.

A entrevistada Mara Núbia de Oliveira, que no período do projeto "Adeus aos Lixões" era diretora da unidade de meio ambiente ressalta que dentro do órgão municipal, se tinha uma percepção da importância do que estava sendo feito. Contudo, ainda não existia uma estrutura, uma base, que propiciasse as possibilidades do suporte desejado por parte da unidade de meio ambiente ao projeto.

Assim sendo, o processo de divulgação permaneceu acontecendo, os envolvidos no projeto continuaram trabalhando com os movimentos ambientais do período, todos em busca de uma causa comum. Porém, como a coleta se demonstrou insuficiente, a população da cidade do Rio Grande que apoiava, entendia a problemática dos resíduos sólidos e suas consequências, passou a cobrar enfaticamente dos responsáveis pelo projeto "Adeus aos Lixões" uma organização na coleta.

Nessa perspectiva, Artur dos Santos Oliveira e Eliane Bacchieri passaram a se dedicar pessoalmente, contudo de maneira informal, pelo controle e fiscalização desse serviço, o que pode ser percebido na citação abaixo.

Por que quando a gente soube que ia ter coleta nessas zonas, eles achavam que iam fazer como quisessem.. Mas, não! Muitas vezes o Artur ia atrás de um caminhão e eu do outro..(risadas) "Pra ver, né?" (DUARTE, Eliane. Entrevista realizada em 2010)

Os esforços para "fazer dar certo" eram imensos. No entanto pouco a pouco, a discussão sobre os resíduos sólidos foi calando-se. A coleta seletiva permaneceu durante algum tempo paralisada no exato ponto que aqui paramos 
de contar ${ }^{9}$. Quanto aos motivos? Talvez nunca sejam descobertos, talvez sejam simplesmente uma junção de fatos que se contrapunham ao ideal almejado. Na verdade, essa é uma discussão que deve ser mais estudada.

Contudo o que, sem dúvida alguma podemos afirmar é que seu legado é vasto e enriquecedor a sociedade rio-grandina. Consciente disso, cita-se Artur de Oliveira para reflexão do leitor.

\begin{abstract}
A dificuldade maior, que se teve, foi a de responder a uma pergunta inconsciente: Se é tão bom, por que ninguém fez ainda fez? E mais uma vez o ser humano abdicava da capacidade de saber que pode criar. Em outras cidades, esta pergunta já não precisou ser feita. Alguém já efetivou a tarefa. Talvez, isso tudo, faça, um dia, parte da nossa história. (OLIVEIRA, 1996, p.16)
\end{abstract}

\title{
$O$ atual contexto
}

\begin{abstract}
A ação da espécie humana, contudo, é de uma qualidade única na natureza. Pois enquanto que as modificações causadas por todos os outros seres são quase sempre assimiláveis pelos mecanismos autoreguladores dos ecossistemas, não destruindo o equilíbrio ecológico, a ação humana possui um potencial enorme desequilibrador. (PÁDUA, 2004, p.13)
\end{abstract}

A cidade do Rio Grande tinha em 2010 aproximadamente duzentos mil habitantes, por esses eram produzidos anualmente uma média de quarenta e quatro mil toneladas de resíduos sólidos ${ }^{10}$. Há ainda, um grande aumento na produção no que tange os últimos anos.

Segundo dados cedidos pela prefeitura, em 2007 foi produzida uma média de quarenta e duas mil cento e cinco toneladas de resíduos, e no ano de 2009 houve um acréscimo de aproximadamente três mil e oitocentas toneladas, ou seja, produzindo quarenta e cinco mil novecentos e cinco toneladas de resíduos. Analisando esses números, se conclui que a produção diária de resíduos entre os anos de 2007 e 2010 no município variou entre cento e dezesseis toneladas por dia em 2007 e pelas projeções pode chegar a média de cento e vinte oito toneladas por dia no fim de 2010.

A lei orgânica do município, foi promulgada em 2 de abril de 1990. Seu artigo 206, institui a obrigatoriedade da coleta seletiva de lixo em toda cidade. Contudo, é preciso ressaltar que essa prática só possui êxito quando a

${ }^{9}$ É importante lembrar que hoje a coleta seletiva é responsabilidade da Secretaria do Meio ambiente e que sua rota é disponibilizada no site da prefeitura municipal.

${ }^{10}$ Segundo o relatório de gestão ambiental do Rio grande, cedido pela Secretária do Meio Ambiente.

Revbea, São Paulo, V. 9, N 1:157-168, 2014. 
sociedade tem interiorizada a responsabilidade social frente a problemática dos resíduos sólidos.

Analisando o que foi exposto até o momento, podemos afirmar que a cidade do Rio Grande foi uma das primeiras do país a refletir e aplicar a coleta seletiva; fomos também pioneiros na construção de cooperativas de catadores e ainda assim, vinte anos depois, esbarramos na negligencia impregnada em nossa cultura.

\begin{abstract}
O lixo é matéria prima fora do lugar. A forma com que uma sociedade trata seu lixo atesta o seu grau de civilização. O tratamento do lixo doméstico, além de ser uma questão tecnológica é antes de tudo uma questão cultural (GRIPPI, 2006, p.1)
\end{abstract}

Dessa forma, como afirma Grippi podemos atribuir o alto índice de resíduos produzidos aos aspectos culturais da sociedade. Somos acometidos todos os dias com situações que podem acarretar reflexões. No entanto, nossa rotina é cada vez mais atribulada, temos diversas tarefas profissionais, uma vida familiar e social que implicam diversas ações. Assim, podemos perceber que não fomos acostumados a parar e analisar o meio em que estamos inseridos e suas especificidades, muito menos a refletir sobre as consequências de nossas atitudes cotidianas na posterioridade.

Estamos inseridos em um contexto onde tudo é descartável e feito para estimular o consumo. Somos costumeiramente envolvidos por propagandas que apresentam a praticidade, modernidade, beleza, e status de seus produtos. Assim, sem perceber acabamos criando novas necessidades, que algumas décadas atrás sequer existiam, como celulares e notebooks. O problema é que aprendemos a comprar e usar esses produtos, mas ignoramos as consequências do destino inapropriado do que não consideramos mais "útil". (RODRIGUES, 2005, p.10)

Assim, ratifico a necessidade emergente de programas de Educação ambiental, pois é necessária uma mudança de comportamento, em relação ao meio ambiente, da sociedade como um todo. É preciso que se comece a respeitar e aprender com o atual contexto, para que as futuras gerações sejam muito mais conscientizadas que a nossa.

Para muitos pode parecer irrisório, mas a realidade é que a discussão aqui empreendida era importante a vinte anos atrás e hoje é urgente, pois cada vez mais estamos buscando soluções para os mais diversos problemas cotidianos na tecnologia e no capitalismo. Logo, construindo um novo mundo, onde a relação entre o ser humano e a natureza está quase extinta (RODRIGUES, 2005, p.20).

Nesse sentido, a ocupação humana de ambientes urbanos mais saudáveis requer do cidadão a condição de ser agente principal no processo de interação com o meio. O ser humano precisa estimular a percepção e se compreender como um constituinte da natureza e não como um ser a parte. 
Esta forma de compreensão pressupõe melhorar as condições ambientais, modificando formas de uso e manutenção do lugar onde habita, pela fixação de hábitos culturais mais saudáveis.

É interessante observar que, visto o raciocínio que aqui estabelecemos, tornou-se possível concluir que a cultura errônea, desleixada com os recursos naturais é muito forte e está amplamente impregnada, restando agora somente o trabalho de estimular o re-pensar, o refletir, para quem sabe com isso gerar um futuro ambientalmente justo e equilibrado

\section{CONSIDERAÇÕES FINAIS}

Dado o exposto, no decorrer deste trabalho foi abordado, na perspectiva da história ambiental, a origem e trajetória do projeto "Adeus aos Lixões", escrito no ano de 1989 e implantado no ano de 1990 na cidade do Rio Grande.

Com todas as informações aqui discorridas, percebeu-se que o projeto "Adeus aos Lixões", embora não se tenha conseguido adaptar efetivamente a sociedade rio-grandina a coleta seletiva diferenciada, estimulou a reflexão sobre a questão ambiental em uma época que ainda não se ouvia tanto falar sobre resíduos sólidos, preservação dos recursos naturais, sustentabilidade e etc. Fato que torna possível perceber seus vestígios, pois mesmo em um contexto nada propicio esses atores sociais conseguiram fomentar algumas mudanças, como a criação de uma secretaria do meio ambiente.

Outro ponto que deve ser aqui mencionado é a importância da relação: ensino, pesquisa e extensão nas universidades, que claramente pudemos perceber nesse trabalho.

$\mathrm{Na}$ perspectiva do ensino, deve-se ressaltar que a academia tem 0 dever de formar não apenas profissionais de áreas especificas, mas também cidadãos comprometidos. Como afirma Artur de Oliveira, é preciso pensar em formar cidadãos para a prática e não só para passar sua vida profissional inteira colocando no papel suas ideias e asserções.

A pesquisa é mais um aspecto do tripé, que deve ser articulado com ensino e extensão, onde suas ações se complementam e contempla a proposta de âmbito universitário.

Com essa noção, partiu-se para a problemática da extensão, que é a parte prática do aprendizado realizado através da teoria. A extensão serve para aproximar a comunidade acadêmica da sociedade, serve para quebrar as barreiras dos antigos e fechados métodos e instaurar um processo educativo de transformação.

Acredita-se na ideia que a educação tem a função de fomentar nos sujeitos sociais uma prática social transformadora, e por isso, julga-se pertinente a sociedade avaliar se esse papel tão importante vem sendo cumprido, principalmente dentro das universidades, que tanto podem fazer em prol desse ideal. É bom lembrar que o "educar" aqui entendido, se define, em 
concordância com Loureiro, pela unicidade dos processos que problematizam os atributos ambientais, culturais e relativos à vida, quando repensa os valores e comportamentos dos grupos sociais; com os que agem nas esferas política e econômica, quando propicia caminhos sustentáveis e sinaliza para novos padrões societários.

\section{REFERÊNCIAS}

AMÂNCIO, C. O Porquê da Educação Ambiental. Net, 2005. Disponível em: <http://www.agronline.com.br/artigos/artigo.php?id=272>

ATA de reunião da Comissão de Reciclagem de resíduos da FURG ํㅜ 002 , do dia 3 de Março de 1990.

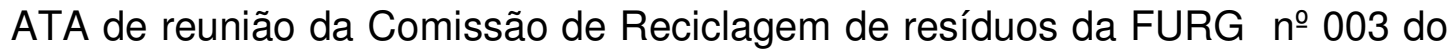
dia 13 de Março de 1990.

CARTAZ do Projeto, 1990.

CELLARD, A. A análise documental. In: POUPART, J. et al. A pesquisa qualitativa: enfoques epistemológicos e metodológicos. Petrópolis, Vozes, 2008.

CONTROLE da Comissão Executiva do Serviço de Destinação de Resíduos de entrega de resíduos por grupo de estudos de discentes da universidade, 1990.

ENTREVISTA com Eliane Bacchiere. (18/11/2010)

ENTREVISTA com Mara Núbia Cezar de Oliveira. (02/12/2010)

FRANCO, B. Análise de conteúdo. 2. ed. Brasília: Líber Livro, 2005.

GRIPPI, S. Lixo: Reciclagem e sua história. Editora Interciência, Rio de Janeiro, RJ, 2005.

JORNAL Agora, 20 de Junho de 1995.

JORNAL Diário da manhã, 15 de Junho de 1995.

LOUREIRO, C.F. Educar, Participar e Transformar em Educação Ambiental. Revista Brasileira de Educação Ambiental. Brasília, 2004, nº zero.

MARTINEZ, P.H. História Ambiental no Brasil: Pesquisa e Ensino. Editora Cortez, São Paulo, SP, 2006.

MENEGOLO, E. O uso da história oral como instrumento de pesquisa sobre o ensino da produção textual. Ciências e cognição, vol.9, 2006.

MINAYO, M.C.S. (Org.). Pesquisa social: teoria, método e criatividade. 22. ed. Rio de Janeiro, Editora Vozes, 2003.

OFÍClO no 791 do ano de 1989 da Fundação Universidade Federal do Rio Grande-FURG. 
OLIVEIRA, A.S.D. Lixões: O preço da ignorância. Editora da FURG, Rio Grande, RS, 1996.

OLIVEIRA, A.S.D. Pra não dizer... que só falei de lixo. Editora da FURG, Rio Grande, RS, 1993.

PÁDUA. J.A. O que é Ecologia. Editora Brasiliense. São Paulo, SP, 2004.

PANFLETO sobre Coleta seletiva, 1990.

PANFLETO do projeto "Adeus aos Lixões", 1989.

PRADO, D.P. Operariado e meio ambiente: Um estudo sobre os trabalhadores da industria de Rio Grande e sua percepção ambiental. Editora da FURG. Coleção Pensar a história sul- rio- grandence, Rio Grande, RS, 2 $2^{\text {a }}$ ed.2001.

PROJETO original "Adeus aos Lixões", entregue em Maio de 1989.

PROJETO original "Florestar", entregue em Julho de 1990.

PROJETO original "Lixo: Educação Comunitária para a coleta diferenciada.", entregue em 1990.

RELATÓRIO sobre "Educação ambiental comunitária", 1990 da comissão executiva do serviço de destinação de resíduos.

RELATÓRIO sobre exposições do lixo reciclado na FURG da comissão executiva do serviço de destinação de resíduos.

RELATÓRIO: Gestão Ambiental no município do Rio Grande, Prefeitura Municipal do Rio Grande, Setembro, 2010.

RIBEIRO, M.A. Ecologizar: Pensando o ambiente humano, Belo Horizonte, Editora Rona, 2000.

RODRIGUES, F.L. Lixo: de onde vem? Para onde vai? Editora Moderna, São Paulo, SP, $2^{\mathrm{a}}$ ed.2005. 